\title{
Corticosteroid therapy and intercurrent illness: the need for continuing patient education
}

\author{
S.R. Peacey, R.M. Pope, K.S. Naik, R.D. Hardern, M.D. Page and \\ P.E. Belchetz
}

Department of Endocrinology, Leeds General Infirmary, Great George Street, Leeds LS1 3EX, UK

\begin{abstract}
Summary: In patients receiving long-term therapeutic or replacement corticosteroids, delayed or inappropriate adjustment of steroid dosage during intercurrent illness may be fatal. We used a questionnaire to assess current levels of patient knowledge, awareness of the need for action during intercurrent illness and the frequency with which steroid warning cards and Medic Alert pendants were carried, in 61 patients on long-term replacement corticosteroids and in $\mathbf{4 0}$ patients receiving long-term therapeutic corticosteroids.

Only 67 of the 101 patients taking corticosteroids were carrying a steroid warning card. Eleven of the 21 Medic Alert owners wore their pendants. Only 18 of the 41 patients in the therapeutic group and 41 of the 60 patients in the replacement group would take appropriate action during an intercurrent illness $(P<0.001)$.

Lack of patient knowledge in this important area emphasizes the need for continuing and effective education of these groups of patients during follow-up. An information sheet detailing the exact changes to be made during intercurrent illness may help reinforce verbal advice.
\end{abstract}

\section{Introduction}

Corticosteroids have been used for many years to treat a wide range of acute and chronic illnesses. The suppressive effect of corticosteroids on the hypothalamic-pituitary-adrenal (HPA) axis varies from patient to patient. ${ }^{1}$ Suppression of the HPA axis may occur after only 5 days therapy with high-dose corticosteroids ${ }^{2}$ and occurs with prolonged therapy at lower doses, although the exact dose, length of therapy and total dose required to do this is not easily evaluated. ${ }^{3}$ In patients with HPA axis suppression induced by long-term corticosteroid therapy and in patients with either primary or secondary adrenal insufficiency, the normal stress-related increase in corticosteroid production will be impaired or absent. These patients are therefore at risk of adrenal crisis and death, should they not receive additional corticosteroids during intercurrent illness, surgery or similar physical stress. ${ }^{4-6}$

Patients who are prescribed corticosteroids should be given a steroid warning card by the dispensing pharmacist or responsible clinician to alert the patient and any attending physician to the need for increased steroids during acute ill health. The wearing of Medic Alert bracelets or pendants may also serve this purpose.

Correspondence: S.R. Peacey, M.R.C.P.

Accepted: 15 October 1992
We carried out a questionnaire-based survey of patients taking long-term replacement or therapeutic corticosteroids, in order to assess the frequency with which steroid warning cards and Medic Alert pendants were carried, and also to assess patient knowledge and awareness of the need for action during intercurrent illness.

\section{Methods}

A questionnaire was completed by 101 adult patients who had been taking corticosteroids for therapeutic $(n=41)$ or replacement $(n=60)$ indications continuously in any dose for longer than 2 months. Patients were interviewed in general medical, rheumatology and endocrinology outpatient departments at Leeds General Infirmary by the clinic doctor. Answers were either of a Yes/No type or there was a choice of responses.

Patients were asked if they had ever been given a steroid warning card or were owners of Medic Alert pendants - proof of carrying either of these was requested at interview. They were also asked if they had ever received advice regarding their steroid dose during intercurrent illness. The response of patients concerning medication during two hypothetical situations was documented: (a) if they were unwell with a fever; and (b) if they were vomiting and unable to take their tablets. Patients were also 
asked whether they were concerned about side effects from their steroid therapy, irrespective of whether given as replacement therapy or in pharmacological doses. If the patient had cognitive impairment and was accompanied by a carer (their spouse/parent) then the questionnaire was completed jointly.

\section{Results}

The results of this study are shown in Tables I-III. In addition we found that $39 \%$ of patients on long-term therapeutic corticosteroids and $23 \%$ of patients on replacement corticosteroids expressed concern about side effects, most usually weight gain and osteoporosis.

\section{Discussion}

Although almost all patients can remember receiving a steroid warning card, the overall percentage of these patients who were carrying their card was
$66 \%$, with greater compliance seen in those patients taking therapeutic steroids. This overall figure is disappointingly low, since greater compliance was found in a survey of steroid card compliance amongst rheumatoid arthritis patients in $1977 .^{7}$

Medic Alert pendants represent an effective way of conveying important information if the patient is unconscious. However, they are currently retailed in the United Kingdom at a minimum of $£ 26.60$ and in our study only $50 \%$ of owners were actually wearing their pendant at interview.

Our study suggests that many patients, particularly those on therapeutic corticosteroids, cannot recall ever being advised regarding corticosteroid requirements during intercurrent illness; this is reflected in the low percentage of appropriate patient responses when faced with an hypothetical illness or vomiting. This may in some cases be a consequence of the primary pathology and resulting therapy (which may have included neurosurgical intervention), though cognitive function was not specifically assessed during this study.

This study reveals that a significant proportion

Table I The proportion of patients owning and carrying steroid warning cards and/or Medic Alert pendants

\begin{tabular}{|c|c|c|c|c|}
\hline \multirow[b]{3}{*}{ Question } & \multicolumn{4}{|c|}{ Treatment indication } \\
\hline & \multicolumn{2}{|c|}{$\begin{array}{l}\text { Therapeutic } \\
(\mathrm{n}=41(\%))\end{array}$} & \multicolumn{2}{|c|}{$\begin{array}{l}\text { Replacement } \\
(\mathrm{n}=60(\%))\end{array}$} \\
\hline & Yes & No & Yes & No \\
\hline $\begin{array}{l}\text { Ever given a } \\
\text { steroid } \\
\text { warning card? }\end{array}$ & $40(98)$ & $1(2)$ & $57(95)$ & $3(5)$ \\
\hline Carrying card today?* & $32(80)$ & $8(20)$ & $35(61)$ & $22(39)$ \\
\hline Owner of Medic Alert? & $4(10)$ & $37(90)$ & $17(28)$ & $43(72)$ \\
\hline $\begin{array}{l}\text { Wearing Medic Alert } \\
\text { today? } \dagger \ddagger\end{array}$ & $2(50)$ & $2(50)$ & $9(53)$ & $8(47)$ \\
\hline
\end{tabular}

*Numbers and percentages refer only to those patients ever given a steroid warning card; †numbers and percentages refer only to owners of Medic Alert pendants; łof the 11 patients wearing Medic Alert pendants, eight were also carrying steroid warning cards.

Table II The proportion of patients in both groups who could recall ever being given advice regarding their steroid dose during intercurrent illness

\begin{tabular}{|c|c|c|c|c|}
\hline \multirow[b]{3}{*}{ Question } & \multicolumn{4}{|c|}{ Treatment indication } \\
\hline & \multicolumn{2}{|c|}{$\begin{array}{l}\text { Therapeutic } \\
(\mathrm{n}=41(\%))\end{array}$} & \multicolumn{2}{|c|}{$\begin{array}{l}\text { Replacement } \\
(\mathrm{n}=60(\%))\end{array}$} \\
\hline & Yes & No & Yes & No \\
\hline $\begin{array}{l}\text { Ever advised regarding } \\
\text { steroid dose if ill? }\end{array}$ & $12(29)^{*}$ & $29(71)$ & $45(75)^{*}$ & $15(25)$ \\
\hline
\end{tabular}

*Fisher's exact test, $P<0.0001$. 
Table III Patient response during two hypothetical illnesses

\begin{tabular}{|c|c|c|c|c|}
\hline \multirow[b]{3}{*}{ Situation } & \multicolumn{4}{|c|}{ Treatment indication } \\
\hline & \multicolumn{2}{|c|}{$\begin{array}{l}\text { Therapeutic } \\
(\mathrm{n}=41(\%))\end{array}$} & \multicolumn{2}{|c|}{$\begin{array}{l}\text { Replacement } \\
(\mathrm{n}=60(\%))\end{array}$} \\
\hline & Appropriate* & Inappropriate & Appropriate* & Inappropriate \\
\hline $\begin{array}{l}\text { If unwell, } \\
\text { e.g. fever }\end{array}$ & $18(44) \dagger$ & $23(56)$ & $41(68) \dagger$ & $19(32)$ \\
\hline If vomiting & $19(46)$ & $22(54)$ & $37(62)$ & $23(38)$ \\
\hline
\end{tabular}

*An appropriate answer to becoming unwell was to increase their steroid dose or seek medical advice, and an appropriate answer to vomiting was to seek medical advice early; †Fisher's exact test, $P<0.001$.

of patients on long-term corticosteroids fail to increase the dose of these drugs during intercurrent illness and also fail to seek medical advice and/or parenteral corticosteroids if vomiting. This is of concern since patients on replacement corticosteroids have by definition an impaired or absent glucocorticoid response to stress, and an unknown proportion of patients on long-term therapeutic corticosteroids will have adrenal suppression and a similarly impaired response to stress. A proportion of patients may be reluctant to increase their corticosteroids, even in the short term, for fear of side effects - even though they should not occur in those patients on replacement doses.

Demonstration of lack of patient knowledge in this important area emphasizes the need for continuing, effective, education during follow-up. Patients attending our endocrine clinic are given a vial of hydrocortisone to keep at home for use by a relative or medical attendant in an emergency. As a result of the findings obtained during this study and in order to reinforce verbal advice given at followup clinics, we have also produced a patient inform-

\section{References}

1. Christy, N.P., Wallace, E.Z. \& Jailer, J.W. Comparative effects of prednisolone and cortisone in suppressing the response of the adrenal cortex to exogenous adrenocorticotropin. J Clin Endocrinol Metab 1956, 16: 1059.

2. Spiegel, R.J., Oliff, A.I., Bruton, J., Vigersky, R.A., Echelberger, C.K. \& Poplack, D.G. Adrenal suppression after short term corticosteroid therapy. Lancet 1979, i: 630-633.

3. Axelrod, L. Glucocorticoid therapy. Medicine 1976, 55: $39-65$.

4. Good, T.A., Benton, J.W. \& Kelley, V.C. Symptomatology resulting from withdrawal of steroid hormone therapy. Arthritis Rheum 1959, 2: 299-321. ation sheet (Figure 1) detailing the required action to be taken during intercurrent illness and vomiting.

PATIENT I.D.

TREATMENT:

\section{DATE COMMENCED:}

In the event of any illness/infection you must DOUBLE your daily steroid dose for THREE DAYS

In the event of vomiting or being unable to swallow your steroid medication you must SEEK MEDICAL ADVICE EARLY since you will require a steroid injection.

Please show this sheet to any medical attendant.

Figure 1 Patient information sheet.

Salassa, R.M., Bennett, W.A., Keating, F.R. \& Sprague, R.G. Postoperative adrenal cortical insufficiency: occurrence in patients previously treated with cortisone. JAMA 1953, 152 1509-1515.

6. Sampson, P.A., Brooke, B.N. \& Winstone, N.E. Biochemical N confirmation of collapse due to adrenal failure. Lancet 1961, i: 1377.

7. Downie, W.W., Leatham, P.A., Rhind, V.M. \& Wright, V. Steroid cards: patient compliance. $\mathrm{Br}$ Med J 1977, 12: 428 